University of South Florida

DIGITAL COMMONS

@ UNIVERSITY OF SOUTH FLORIDA
Digital Commons @ University of

South Florida

$12-1-2004$

\title{
Evaluation of Automated Vehicle Technology for Transit - 2016 Update
}

CUTR

Follow this and additional works at: https://digitalcommons.usf.edu/cutr_nctr

\section{Recommended Citation}

"Evaluation of Automated Vehicle Technology for Transit - 2016 Update," National Center for Transit Research (NCTR) Report No. CUTR-NCTR-RR-2016-14, Center for Urban Transportation Research, University of South Florida, 2004.

DOI: https://doi.org/10.5038/CUTR-NCTR-RR-2016-14

Available at: https://scholarcommons.usf.edu/cutr_nctr/64

This Technical Report is brought to you for free and open access by the National Center for Transit Research (NCTR) Archive (2000-2020) at Digital Commons @ University of South Florida. It has been accepted for inclusion in Research Reports by an authorized administrator of Digital Commons @ University of South Florida. For more information, please contact digitalcommons@usf.edu. 


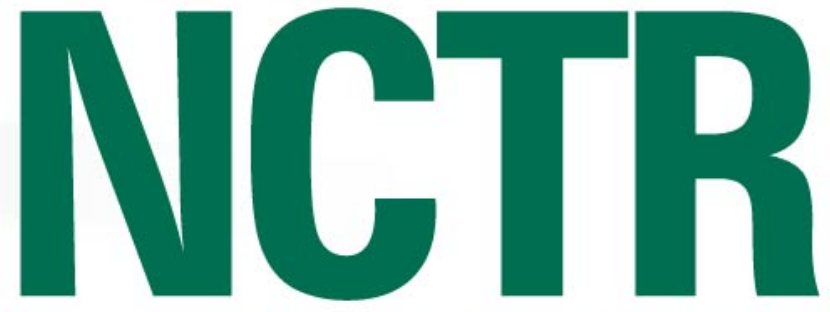

NATIONAL CENTER for TRANSIT RESEARCH

\section{Evaluation of Automated Vehicle Technology for Transit - 2016 Update}

Final Report

\section{April 2016}

PROJECT NO. 2117-9060-21

PREPARED FOR

National Center for Transit Research (NCTR) 


\section{Disclaimer}

The contents of this report reflect the views of the authors, who are responsible for the facts and the accuracy of the information presented herein. This document is disseminated under the sponsorship of the University of South Florida's National Center for Transit Research (NCTR) in the interest of information exchange. The University of South Florida and the National Center for Transit Research assume no liability for the contents or use thereof.

The opinions, findings, and conclusions expressed in this publication are those of the authors and not necessarily those of the National Center for Transit Research. 


\title{
Evaluation of Automated Vehicle Technology for Transit - 2016 Update
}

\author{
Prepared for:

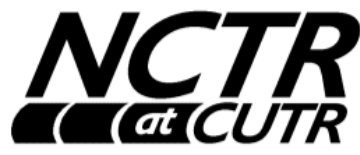 \\ National Center for Transit Research \\ University of South Florida \\ Joel Volinski, Project Manager
}

Prepared by:

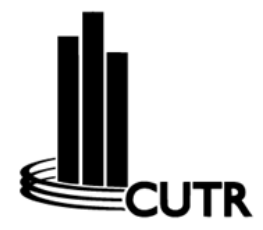

Center for Urban Transportation Research

University of South Florida

Brian Pessaro, AICP

Final Report

April 2016 


\section{Metric Conversion}

\begin{tabular}{|c|c|c|c|c|}
\hline SYMBOL & WHEN YOU KNOW & MULTIPLY BY & TO FIND & SYMBOL \\
\hline \multicolumn{5}{|c|}{ LENGTH } \\
\hline in & inches & 25.4 & millimeters & $\mathrm{mm}$ \\
\hline $\mathrm{ft}$ & feet & 0.305 & meters & $\mathrm{m}$ \\
\hline yd & yards & 0.914 & meters & $\mathrm{m}$ \\
\hline mi & miles & 1.61 & kilometers & $\mathrm{km}$ \\
\hline \multicolumn{5}{|c|}{ VOLUME } \\
\hline fl oz & fluid ounces & 29.57 & milliliters & $\mathrm{mL}$ \\
\hline gal & gallons & 3.785 & liters & $\mathrm{L}$ \\
\hline $\mathrm{ft}^{3}$ & cubic feet & 0.028 & cubic meters & $m^{3}$ \\
\hline$y d^{3}$ & cubic yards & 0.765 & cubic meters & $\mathrm{m}^{3}$ \\
\hline \multicolumn{5}{|c|}{ Note: volumes greater than $1000 \mathrm{~L}$ shall be shown in $\mathrm{m}^{3}$} \\
\hline \multicolumn{5}{|c|}{ MASS } \\
\hline $\mathbf{O z}$ & ounces & 28.35 & grams & g \\
\hline lb & pounds & 0.454 & kilograms & kg \\
\hline $\mathbf{T}$ & short tons (2000 lb) & 0.907 & $\begin{array}{c}\text { megagrams } \\
\text { (or metric ton) }\end{array}$ & $\mathrm{Mg}($ or " $\mathrm{t}$ ") \\
\hline \multicolumn{5}{|c|}{ TEMPERATURE (exact degrees) } \\
\hline${ }^{\circ} \mathbf{F}$ & Fahrenheit & $\begin{array}{c}5(F-32) / 9 \text { or }(F- \\
32) / 1.8\end{array}$ & Celsius & ${ }^{\circ} \mathrm{C}$ \\
\hline
\end{tabular}




\section{Technical Report Documentation}

\begin{tabular}{|c|c|c|c|c|}
\hline $\begin{array}{l}\text { 1. Report No. } \\
\text { n/a }\end{array}$ & \multicolumn{2}{|c|}{ 2. Government Accession No. } & \multicolumn{2}{|c|}{ 3. Recipient's Catalog No. } \\
\hline \multirow{2}{*}{\multicolumn{3}{|c|}{$\begin{array}{l}\text { 4. Title and Subtitle } \\
\text { Evaluation of Automated Vehicle Technology in Transit - } 2016 \text { Update }\end{array}$}} & \multicolumn{2}{|l|}{$\begin{array}{l}\text { 5. Report Date } \\
\text { April } 2016\end{array}$} \\
\hline & & & \multicolumn{2}{|c|}{ 6. Performing Organization Code } \\
\hline \multicolumn{3}{|l|}{$\begin{array}{l}\text { 7. Author(s) } \\
\text { Brian Pessaro, AICP }\end{array}$} & \multicolumn{2}{|c|}{ 8. Performing Organization Report No. } \\
\hline \multirow{2}{*}{\multicolumn{3}{|c|}{$\begin{array}{l}\text { 9. Performing Organization Name and Address } \\
\text { National Center for Transit Research } \\
\text { Center for Urban Transportation Research (CUTR) } \\
\text { University of South Florida } \\
4202 \text { E. Fowler Avenue, CUT100 } \\
\text { Tampa, FL 33620-5375 }\end{array}$}} & \multicolumn{2}{|c|}{ 10. Work Unit No. (TRAIS) } \\
\hline & & & \multicolumn{2}{|c|}{$\begin{array}{l}\text { 11. Contract or Grant No. } \\
\text { 2117-9060-21 }\end{array}$} \\
\hline \multirow{2}{*}{\multicolumn{3}{|c|}{ 12. Sponsoring Agency Name and Address }} & \multicolumn{2}{|c|}{$\begin{array}{l}\text { 13. Type of Report and Period Covered } \\
\text { Final Report }\end{array}$} \\
\hline & & & \multicolumn{2}{|c|}{ 14. Sponsoring Agency Code } \\
\hline \multicolumn{5}{|l|}{ 15. Supplementary Notes } \\
\hline \multicolumn{5}{|c|}{$\begin{array}{l}\text { 16. Abstract } \\
\text { In January 2015, the National Center for Transit Research (NCTR) published a report summarizing the state of public } \\
\text { transportation vehicle automation entitled "Evaluation of Automated Vehicle Technology for Transit." This } 2016 \text { update } \\
\text { presents the latest information on this topic. Europe has been at the forefront of testing shared autonomous vehicles. The } \\
\text { European Union is funding demonstrations and showcases of small autonomous shuttle buses in } 10 \text { cities across Europe } \\
\text { under a program called CityMobil2. Two French companies, EasyMile and NAVYA, have emerged as commercial } \\
\text { autonomous shuttle bus manufacturers. EasyMile provided the shuttles for the CityMobil2 project and also launched a } \\
\text { separate demonstration in the Netherlands under the name WEPod. It has also signed an agreement with the Contra Costa } \\
\text { Transportation Authority in California to test the shuttles in a commercial office park. NAVYA recently signed its first } \\
\text { agreement with the Swiss public transportation company CarPostal to run autonomous shuttles in the Swiss city of Sion. In } \\
\text { Minnesota, the Minnesota Valley Transit Authority has received funding from the Federal Transit Administration (FTA) to } \\
\text { equip } 11 \text { of its buses with an updated version of the driver assist system it uses for bus on shoulder operations. }\end{array}$} \\
\hline \multicolumn{2}{|c|}{$\begin{array}{l}\text { 17. Key Words: Automated vehicles, autonomous vehicles, } \\
\text { transit, shared autonomous vehicles, CityMobil2, EasyMile, } \\
\text { NAVYA }\end{array}$} & \multicolumn{3}{|c|}{ 18. Distribution Statement } \\
\hline $\begin{array}{l}\text { 19. Security Classif. (of this report) } \\
\text { Unclassified }\end{array}$ & \multicolumn{2}{|c|}{$\begin{array}{l}\text { 20. Security Classif. (of this pag } \\
\text { Unclassified }\end{array}$} & \begin{tabular}{|c|} 
21. No. of Pages \\
22
\end{tabular} & 22. Price \\
\hline
\end{tabular}




\section{Table of Contents}

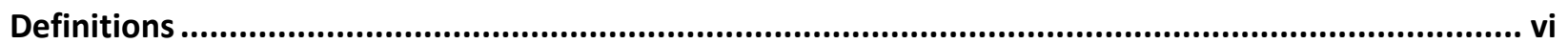

\section{Executive Summary}

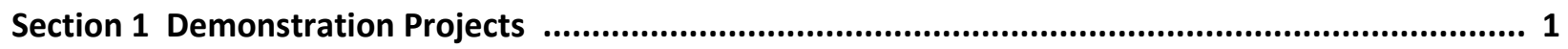

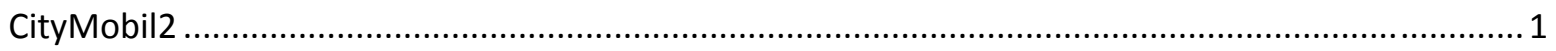

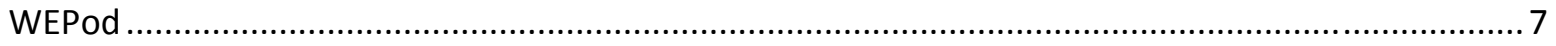

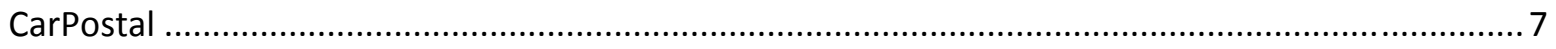

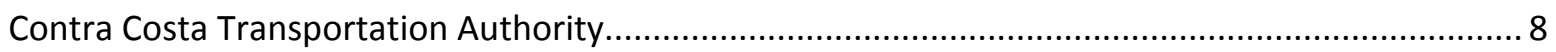

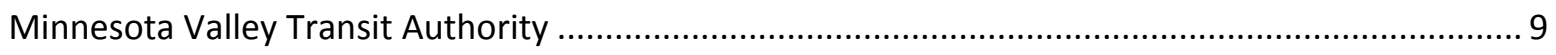

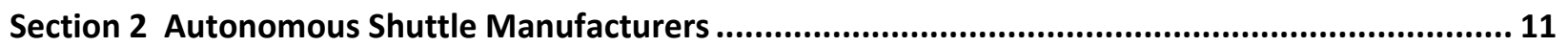

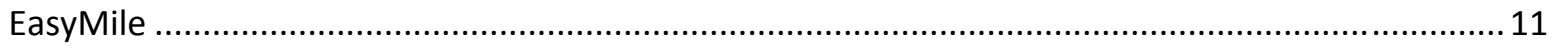

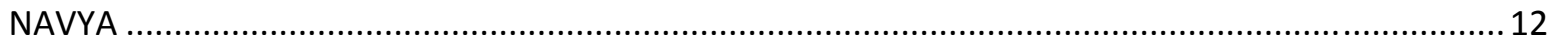

\section{List of Figures}

Figure 1. Robosoft's RoboCITY Shuttle at Trikala Demonstration................................................... 2

Figure 2. EasyMile's EZ10 Shuttle at Lausanne Demonstration ........................................................... 2

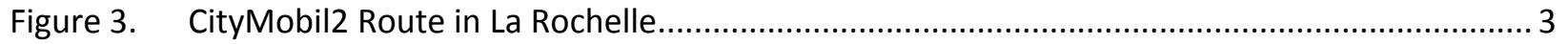

Figure 4. CityMobil2 Shuttle Route in Lausanne (EPFL) ............................................................ 5

Figure 5. Wheelchair-Accessible EZ10 Shuttle Vehicle by EasyMile ................................................... 6

Figure 6. Proposed WEPod Route on Campus of Wageningen University............................................ 7

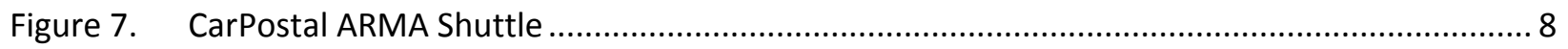

Figure 8. EZ10 Autonomous Electric Shuttle by EasyMile ................................................................ 11

Figure 9. EZ10 Model Showing Handicap Accessibility by EasyMile ................................................ 11

Figure 10. ARMA Autonomous Electric Shuttle............................................................................... 12

\section{List of Tables}

Table 1. CityMobil2 Showcase and Demonstration Cities ............................................................ 1 


\section{Definitions}

Autonomous vehicle - A vehicle capable of sensing its environment and navigating without human input.

BOS (bus-on-shoulder) operation -A transportation strategy in which public transportation buses are allowed to bypass traffic congestion by using the highway shoulder when speeds in the general purpose lanes drop below a certain threshold (e.g., $35 \mathrm{mph}$ ).

GPS (Global Position System) -A navigational system using satellite signals to fix the location of a radio receiver on or above the earth's surface.

HUD (head-up display) - A transparent display that presents data without requiring users to look away from their usual viewpoints.

Lane-keep assist - A technology designed to alert the driver when the system detects that the vehicle is about to deviate from a traffic lane.

Lidar - A device similar in operation to radar that emits pulsed laser light instead of microwaves.

LED (light emitting diode) - A semiconductor diode that emits light when a voltage is applied to it and that is used especially in electronic devices as for an indicator light.

Magnetic guidance system - A technology that controls the steering of a vehicle through a combination of magnetic markers embedded in the road surface at set intervals, magnetic sensor bars under the vehicle, and a steering actuator.

Radar - A device that sends out radio waves for determining the position and speed of a moving object. 


\section{Executive Summary}

In January 2015, the National Center for Transit Research (NCTR) published a report summarizing the state of public transportation vehicle automation entitled "Evaluation of Automated Vehicle Technology for Transit." The report was prepared for the Florida Department of Transportation (FDOT), which wanted to better understand the state of the industry in regards to automated vehicle (AV) technology for public transit. The report found that unlike the automotive industry, which has invested heavily in the research and development of AV technology applications in personal automobiles, neither public transit agencies nor bus manufacturers in America have expressed a similar level of interest. When NCTR contacted several U.S. bus manufactures to ask if they planned to offer AV technology in any of their models, only Nova Bus/Volvo gave a positive response, noting that it was considering adding a pedestrian/bicyclist warning system to its buses. However, strictly speaking, this would be classified as a driver assist system unrelated to vehicle automation.

The report also found only two operational uses of AV technology by U.S. transit agencies, both of which are prototype systems developed by university engineers and funded by grants from the Federal Transit Administration (FTA). The Minnesota Valley Transit Authority (MTVA) in Apple Valley equipped several of its buses with a global position system (GPS)-based lane-keep assist and collision avoidance system that is used when a bus rides on a highway shoulder to bypass congestion. However, strictly speaking, this, too, is a driver assist system, because the bus driver is in control of the steering and acceleration at all times. Lane Transit District in Eugene, Oregon, uses a magnetic guidance system for precision docking of its Emerald Express (EmX) bus rapid transit (BRT) system at three stations. Both systems were evaluated by the Center for Urban Transportation Research (CUTR) and reported in "Cedar Avenue Driver Assist System Evaluation Report" (FTA Report No. 0010). The evaluation of the precision docking system used by Lane Transit District is pending publication by FTA.

Since the time of the 2015 report, there have been some positive developments in the area of AV technology for public transit, particularly in Europe, that make a 2016 update worthwhile. The European Union (EU) has been funding demonstrations of fully-automated shuttles in several European cities under a project named CityMobil2. The manufacturer of the shuttle used for the CityMobil2 project is EasyMile, a joint venture between the French automobile manufacturer Ligier and the French robotics systems company Robosoft. In addition to the CityMobil2 project, EasyMile will soon have demonstration projects of its autonomous shuttle in the Netherlands, Singapore, and the United States. Another European manufacturer of autonomous shuttles is NAVYA, also a French company, which has sold two shuttles to the Swiss public transportation company CarPostal, which will be running them on public roads in the Swiss city of Sion beginning in summer 2016.

In the United States, the MVTA received additional funds from FTA to outfit 11 additional buses with a new and improved version of its driver assist system. These buses are expected to go into revenue service in summer 2016. While perhaps not as intriguing as the demonstrations of the autonomous 
shuttles in Europe, this second iteration is significant because it shows that MVTA and FTA saw enough value in AV technology to invest in it further.

A second new project involves NAVYA, which will soon begin a demonstration project of its autonomous shuttle in the United States with the Contra Costa Transportation Authority (CCTA) in northern California. It will involve testing two of the shuttles in a business park, with trials expected to begin in summer 2016, one at GoMentum Station and one at the Bishop Ranch business park.

This report summarizes what is known about these projects based on available information. There has been much development in the area of autonomous shared vehicles, but almost all of it is occurring overseas, especially in Europe. Fortunately, the autonomous shared vehicles that are being tested in Europe are not "one-off" prototypes but rather are commercially-manufactured vehicles. Florida could and should take advantage of these new developments in shared autonomous vehicles. Test facilities are available in Orlando and Tampa, and Florida laws related to autonomous vehicles are more flexible than California laws. For example, California law requires that all autonomous vehicles be equipped with a steering wheel, brake pedal, and accelerator. Because the autonomous shuttles manufactured by EasyMile and NAVYA do not have these components, CCTA will have to get regulatory approval via a change in state law. By contrast, Florida law simply requires that autonomous vehicles "have a means to engage and disengage the autonomous technology which is easily accessible to the operator" (319.145 (1)(a), Florida Statutes).

An important observation from the test results in Europe is that any successful testing of shared autonomous vehicles must include a fleet management component. Although this may be obvious to the relatively small number of experts who specialize in this area of transportation, it needs to be pointed out to a wider audience who may have unrealistic expectations. The bottom line is a human will still need to monitor the shuttles remotely from a control room. Furthermore, the current state of AV technology requires, for safety reasons, that a trained professional be on-board the vehicle.

Europe's CityMobil2 demonstrations have provided important lessons on just how difficult it is to operate fully autonomous vehicles in an urban environment. Unless the shuttles are operating in a fully grade-separated right-of-way, they will have to react to a host of external obstacles on a daily basis such as illegally- or poorly-parked vehicles, delivery vehicles, and construction activities. Furthermore, the CityMobil2 demonstrations have experienced random vehicle malfunctions. It was noted by the evaluators that there were situations in which it would have been impossible to continue operations had there not been a back-up operator on board. This is not a criticism; it is simply an honest assessment of the current state of the technology. However, the technology is increasingly improving, and with each demonstration project the body of knowledge on shared autonomous vehicles is expanding. 


\section{Section 1 Demonstration Projects}

\section{CityMobil2}

CityMobil2 is a European Union (EU) funded research project whose main goal is to remove barriers to the deployment of a fully-automated bus. Its total budget is $15 \mathrm{M} €(\$ 16.9 \mathrm{M})$, of which 9.5 $\mathrm{M} €(\$ 10.7 \mathrm{M})$ came from the EU and the remainder from various project partners. The project length is 48 months (2012-2016) and includes demonstrations and showcases of small automated buses in 10 cities across Europe, as shown in Table 1. The showcases are 2-3-day exhibits, and the demonstrations are subdivided into large-scale (1-4 buses) lasting up to 4 months, and small-scale ( 6 buses and up to 6 months).

Table 1. CityMobil2 Showcase and Demonstration Cities

\begin{tabular}{|l|c|c|}
\hline \multicolumn{1}{|c|}{ City, Country } & Demo or Showcase & Year \\
\hline León, Spain & Showcase & 2014 \\
\hline Bordeaux, France & Showcase & 2015 \\
\hline Warsaw, Poland & Showcase & 2016 \\
\hline Oristano, Italy & Small Demo & 2014 \\
\hline Vantaa, Finland & Small Demo & 2015 \\
\hline San Sebastian, Spain & Small Demo & 2016 \\
\hline Sophia Antipolis, France & Small Demo & 2016 \\
\hline LaRochelle, France & Large Demo & $2014 / 15$ \\
\hline Lausanne, Switzerland & Large Demo & $2014 / 15$ \\
\hline Trikala, Greece & Large Demo & $2015 / 16$ \\
\hline
\end{tabular}

The CityMobil2 website includes background information about the project, the latest lessons learned from the demonstrations, and newsletters, project deliverables, and presentations made to the CityMobil2 Reference Group, a stakeholder group comprising members of local transportation authorities and others with an interest in public transportation automation. According to the website, CityMobil2 aims to deliver the following outcomes:

- An automated road transport service running for at least 6 months at 5 sites across Europe (note: this has changed since the beginning of the project; there have been 7 demonstrations of varying lengths)

- Guidelines to design and implement an automated road transport system (ARTS)

- Improved understanding of the interaction between automated vehicles and other road users

- A legal framework proposal for certifying automated road transport systems in Europe

- Showcases at numerous sites across Europe

- Technical specifications for interoperable automated road transport systems, including a communications architecture

Five manufacturers responded to the initial call for ARTS, and two were selected, Robosoft and Induct. However, Induct was excluded shortly afterwards due to solvency issues. In its place, a new supplier, 
EasyMile, was identified and selected. Both Robosoft and EasyMile are French companies, and EasyMile is a joint venture between Robosoft and Ligier, a French vehicle manufacturer.

The CityMobil2 project has used two models of autonomous vehicles for the demonstrations. The Robosoft model is called the RoboCITY (see Figure 1). It is battery-powered (lead acid) and has capacity for 10 passengers ( 6 seated, 4 standing). This vehicle is a prototype and will not be continued after the CityMobil2 project is completed because EasyMile, of which Robosoft is a part, is now fully focused on the EZ10 shuttle.

The EZ10 (see Figure 2) has capacity for 12 passengers ( 6 seated, 6 standing) and is wheelchair-accessible. It is batterypowered (lithium-ion). It has a cruising speed of $20 \mathrm{~km} / \mathrm{h}(12.4 \mathrm{mph})$ and a maximum speed of $40 \mathrm{~km} / \mathrm{k}$ (24.8 mph). The vehicle is based on the chassis of a standard electric minibus.

Additional information on the EZ10 shuttle and EasyMile can be found later in this report.

\section{La Rochelle Demonstration}

La Rochelle is a medium-size city of 146,000 inhabitants on the west coast of France. The original plan called for a sixmonth demonstration, with six shuttles operating in the city center and linking the railway station, the old harbor area, and the University of La Rochelle. Service was to run from Monday to Saturday and be free of charge to riders.

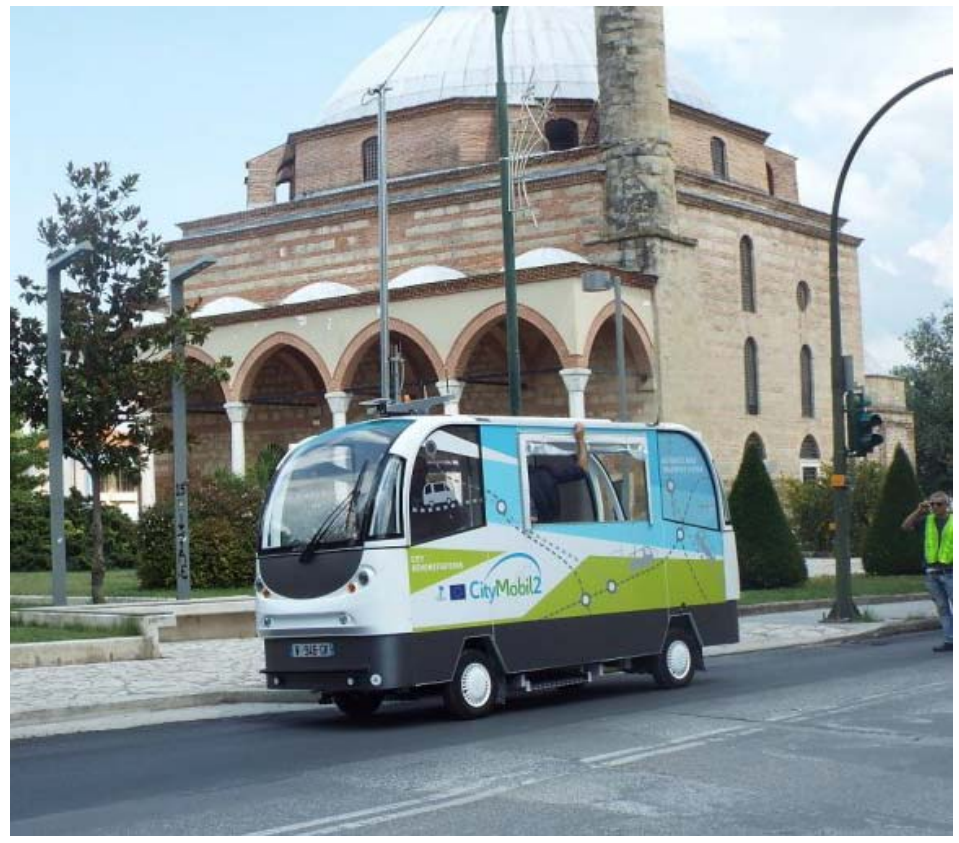

Source: CityMobil2

Figure 1. Robosoft's RoboCITY Shuttle at Trikala Demonstration

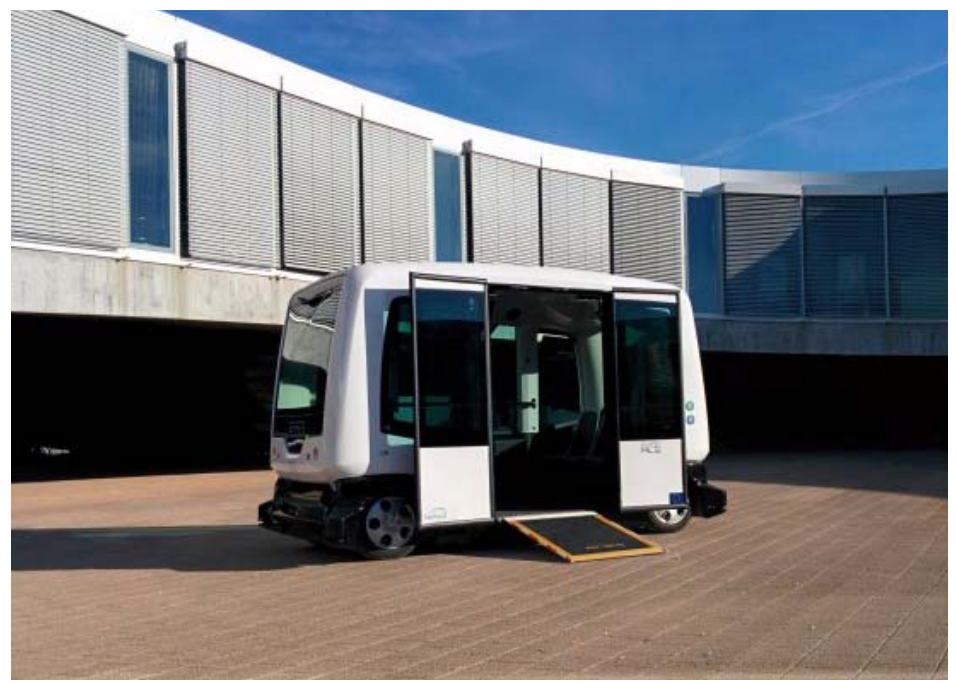

Source: CityMobil2

Figure 2. EasyMile's EZ10 Shuttle at Lausanne Demonstration 
Several modifications were made to the original demonstration plan. First, the duration was reduced from six to four months (from mid-December 2014 to the end of April 2015) ${ }^{1}$ as a result of delays in the delivery of the vehicles and getting the needed legal authorization. Because there is no legal framework in France for automated vehicles, the La Rochelle partners had to obtain special temporary permission from French authorities. The route was modified as well. Specifically, the connection with the train station was removed because of technical difficulties with an unstable GPS signal encountered on a stretch of the route that passed through a small park with trees. This issue has been resolved in the newer fleet of vehicles supplied by EasyMile.

There were three operational phases. In the initial phase, three shuttles operated on a segment linking the Aquarium with the Tourist office (green line in Figure 3). The second phase began in January 2015 and added a new segment and three more vehicles (solid blue line in Figure 3 ). The third and final phase connected the two segments into one continuous route (dashed blue and green line in Figure 3). Because of the delays, the third phase did not start until March 2015, so that the route was continuous only for two of the four months.

During the four-month demonstration, the shuttles carried approximately 15,000 passengers. A back-up operator was on board at all times to take control in case of technical failure. The vehicles were in autonomous mode $94 \%$ of the time during the demonstration and in manual mode $6 \%$

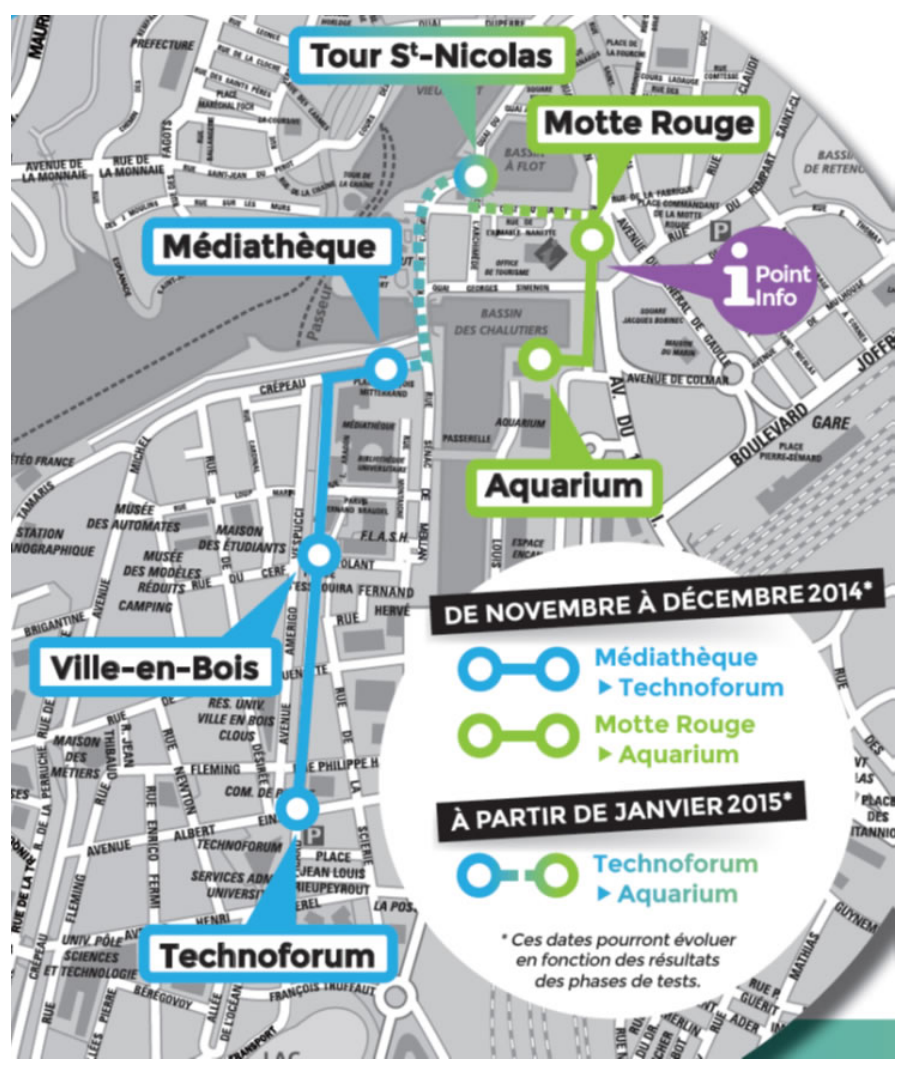

Source: CityMobil2 of the time. Under normal circumstances (e.g., when approaching or leaving one of the stops/stations), the maximum acceleration and deceleration were lower and more consistent when the vehicle was in autonomous mode than in manual mode. However, it was also reported that the deceleration rate was unexpectedly higher under autonomous mode when there was unexpected deceleration (e.g., someone or something getting in the path of the shuttle). The reason is under analysis, but it was speculated that

\footnotetext{
${ }^{1}$ Presentation from third meeting of CityMobil2 Reference Group, June 23, 2015, Lausanne, Switzerland, http://www.citymobil2.eu/en/City-activities/Reference-Group/, La Rochelle CityMobil2 demo preliminary results, Matthieu Graindorge, La Rochelle.
} 
it may have been caused by late detection of obstacles by the lidar sensors. Similarly, a significant number of jerks (recorded in $\mathrm{m} / \mathrm{s}^{3}$ ) was reported when the vehicle was in autonomous mode. ${ }^{2}$

According to meeting notes from the third meeting of the CityMobil2 Reference Group, which met in Lausanne, Switzerland on June 23, 2015, several important lessons were learned. Some were negative, but should not be counted as a strike against the ARTS concept. This was CityMobil2's first large-scale demonstration, so it is to be expected that there would be "bumps in the road." Unlike the demonstration in Lausanne (described next), the La Rochelle demonstration did not include a fleet management component, which proved to be detrimental. Random vehicle malfunctions occurred, and had there not been a back-up operator on board to take over manually, it would have been impossible to continue operating. It was noted that operating a fully-autonomous vehicle in an urban environment is not easy because of external factors such as illegal parking and road construction. It also was noted that having clearer and more identifiable markings along the route would have contributed to better interaction with pedestrians and cyclists. In addition, the vehicles manufactured for the La Rochelle demonstration were not accessible by persons with disabilities, so the project could not truly be considered a new form of public transportation but rather an experimental new transportation system. Other types of analyses were conducted, including surveys of riders, bicyclists, pedestrians, the general public, and local stakeholders. As of the writing of this report, these have not yet been published online.

\section{Lausanne Demonstration (EPFL)}

The Swiss Federal Institute of Technology (Ecole Polytechnique Fédérale de Lausanne, EPFL), located in Lausanne, was the site of CityMobil2's second large-scale demonstration. The demonstration lasted five months, from April to August 2015. The automated shuttles were used to reduce the last-mile gap between the campus metro station and the main areas of campus.

Six shuttles operated on a $1.5-\mathrm{km}(0.93-$ mile) route that connected the north and south ends of the campus (see Figure 4). The route was originally supposed to have six stops, including one at the metro station on the north end (shown as M1 on the map). However, this stop was removed due to building construction on the campus. Service ran from 7:45 AM to 10:00 PM Monday through Friday. From midJuly to late August, the project included an option for riders to request a shuttle using a smartphone app. This was accomplished by switching two of the shuttles to "on-demand mode" while the other two continued to run on a fixed schedule. About 1,000 people were reported to have used the app. The vehicle fleet was provided by EasyMile and fleet management was provided by BestMile. Almost 7,000 passengers boarded the shuttles during the five-month demonstration.

\footnotetext{
${ }^{2}$ Presentation from third meeting of CityMobil2 Reference Group, June 23, 2015, Lausanne, Switzerland, http://www.citymobil2.eu/en/City-activities/Reference-Group/, La Rochelle CityMobil2 demo preliminary results, Mike McDonald, TRG.
} 
Similar to the demonstration in La Rochelle, legal authorization was needed to test driverless vehicles on roads. Permission was granted at the cantonal level by the road traffic office with several conditional requirements: that there be a groom (attendant) on board the shuttle who could take control in case of technical failure, there be a maximum of 9 persons on board, and the maximum shuttle speed would be 15 $\mathrm{km} /$ hour (9.3 mph). ${ }^{3}$ The Lausanne demonstration had another similarity to the La Rochelle demonstration-physical obstacles in the path of the shuttles, including badly-parked vehicles, delivery vehicles, and construction activities. However, unlike the La Rochelle demonstration, the Lausanne demonstration included a fleet management component, which was provided by BestMile.

Whenever the automated shuttle encountered an obstacle, it would come to a halt and a BestMile operator in a remote control room would assess the situation through cameras and decide if the shuttle could continue on its way.

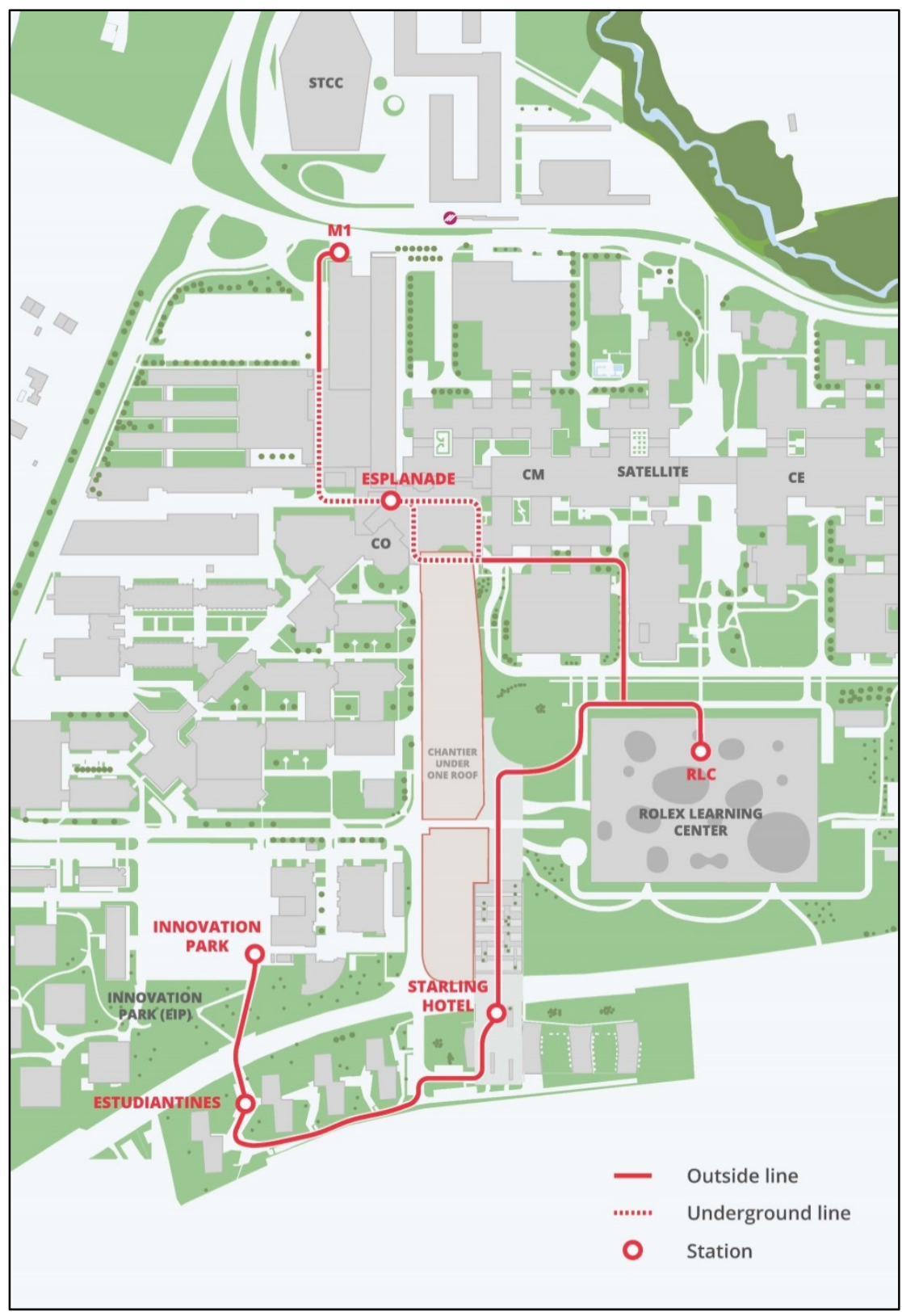

Source: EPFL

Figure 4. CityMobile2 Route in Lasaunne (EPFL Campus)

\footnotetext{
${ }^{3}$ Presentation from third meeting of the CityMobil2 Reference Group, June 23, 2015, Lausanne (Switzerland)
} http://www.citymobil2.eu/en/upload/Presentations/Lausanne demo.pdf. 
An external factor not encountered in La Rochelle but encountered in Lausanne was a summer heat wave. This led to having to operate the vehicle's air conditioner almost the entire time, which impacted the batteries, which, in turn, impacted autonomous operations. Furthermore, the high temperatures and dry weather made the roads dusty, which hindered the ability of the

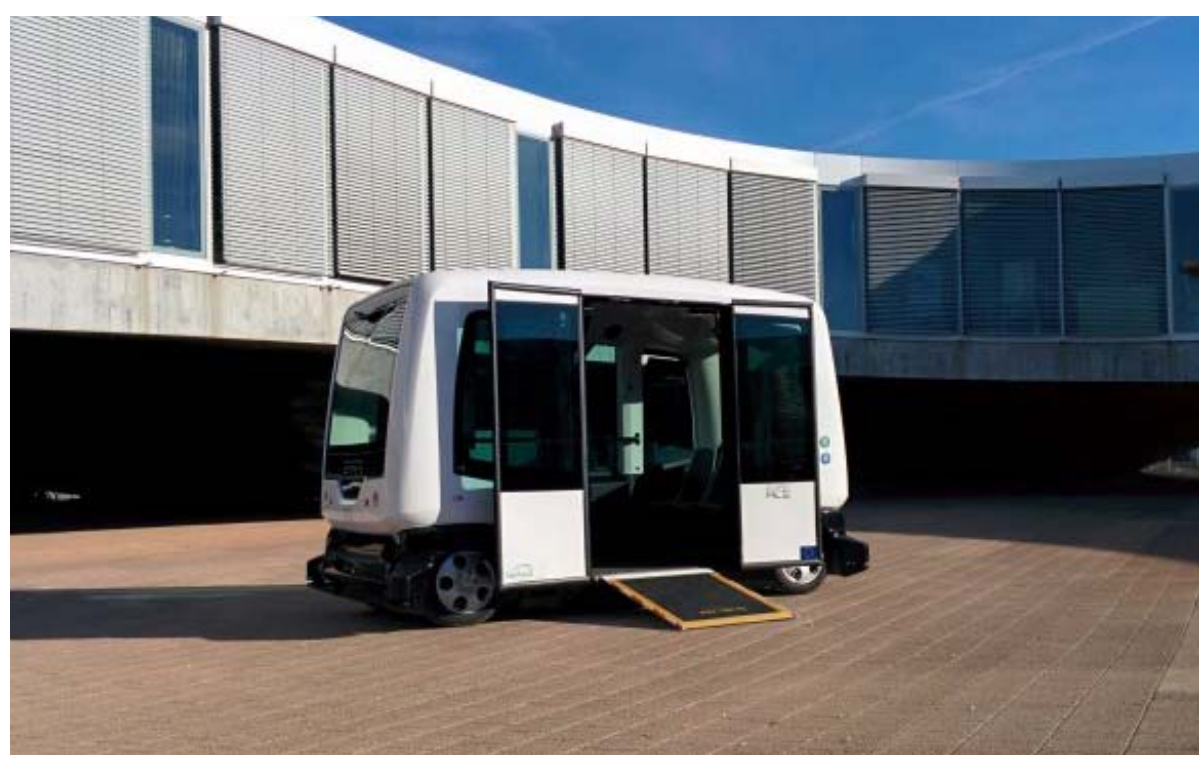

Source: CityMobil2

Figure 5. Wheelchair-Accessible EZ10 Autonomous Vehicle by EasyMile vehicles' lidar sensors to detect obstacles. In terms of safety, there was one reported collision between two shuttles, with light damage to a bumper, and one collision with a cyclist, with no physical damage to either the shuttle or the cyclist. Both occurred within the first two months of operation. ${ }^{4}$ On a positive note, the shuttles used in the Lausanne demonstration were accessible by persons with disabilities, which was an improvement over the vehicles that were used in the La Rochelle demonstration (see Figure 5).

\section{Trikala Demonstration}

Trikala is a medium-size city of about 76,000 in the Thessaly region of Greece. The CityMobil2 demonstration in Trikala lasted from November 2015 to February 2016 using vehicles produced by Robosoft (see Figure 1 ). Four automated shuttles operated on a $2.5-\mathrm{km}(1.55-\mathrm{mile})$ route that linked the historical city center with the central business district. The vehicles operated in a dedicated lane alongside other road users, including car drivers, pedestrians, and cyclists. There were six stops, including stops at the city bus terminal and an underground parking lot. Similar to the demonstrations in La Rochelle and Lausanne, special legislation was required to allow demonstration of the automated buses on public roads. The legislation that was passed authorized the driver to not be in the vehicle but rather in a remote control room. For this reason, the Trikala demonstration included a fleet management component; although the buses were fully automated with onboard navigation and obstacle detection systems, they were monitored by an operator in a remote control center who could override the system.

${ }^{4}$ Ibid. 
By the end of the demonstration, the shuttles had made 1,490 trips and carried more than 12,000 passengers. Most of the riders were tourists, as opposed to residents using it for local transport. As with the demonstrations in La Rochelle and Lausanne, there were some important lessons learned from the Trikala demonstration. In an interview posted on the CityMobil2 website, the mayor of Trikala reported that the project was initially met with suspicion by the local populace, with typical reactions including "Why do we need 'blind' buses?" or "The bus drivers will lose their jobs!" However, the suspicion subsided as the project went on. Additionally, there was some negative reaction to the removal of 70 on-street parking spaces to make room for the dedicated bus lane. There was one serious technical failure that occurred when a bus left the path and went onto a sidewalk. However, the bus's built-in security systems worked as designed, and the bus stopped before striking a kiosk.

\section{WEPod}

In January 2016, the province of Gelderland in the Netherlands launched the WEPod project (www.wepods.com) at a project cost of $3.5 \mathrm{M} €(\$ 4 \mathrm{M})$, with all funds coming from Gelderland. The State of the Netherlands amended its traffic laws to allow testing on public roads. Although not officially part of CityMobil2, the WEPod demonstration will have similarities to CityMobil2. For instance, it will use the EZ10 shuttles developed by EasyMile. Similar to the CityMobil2 demonstration in Lausanne, the WEPods will operate on a university campus, in this case Wageningen University (see proposed route map in Figure 6). Initially, the route will be limited to a circular loop around the campus. If the testing is successful, the route will be expanded to provide service to the Ede-Wageningen railway station.

Similar to the EasyMobil2 demonstrations, the WEPods will operate autonomously and react to pedestrians and other vehicles through the use of cameras, radar, and laser-based sensors. An operator in a remote control room will receive signals at pre-defined points and whenever the bus stops. The control room operator will examine the situation and make the appropriate response. Passengers will be able to contact the control room at any time. During the test phase, the maximum speed of the buses will be $25 \mathrm{~km} /$ hour

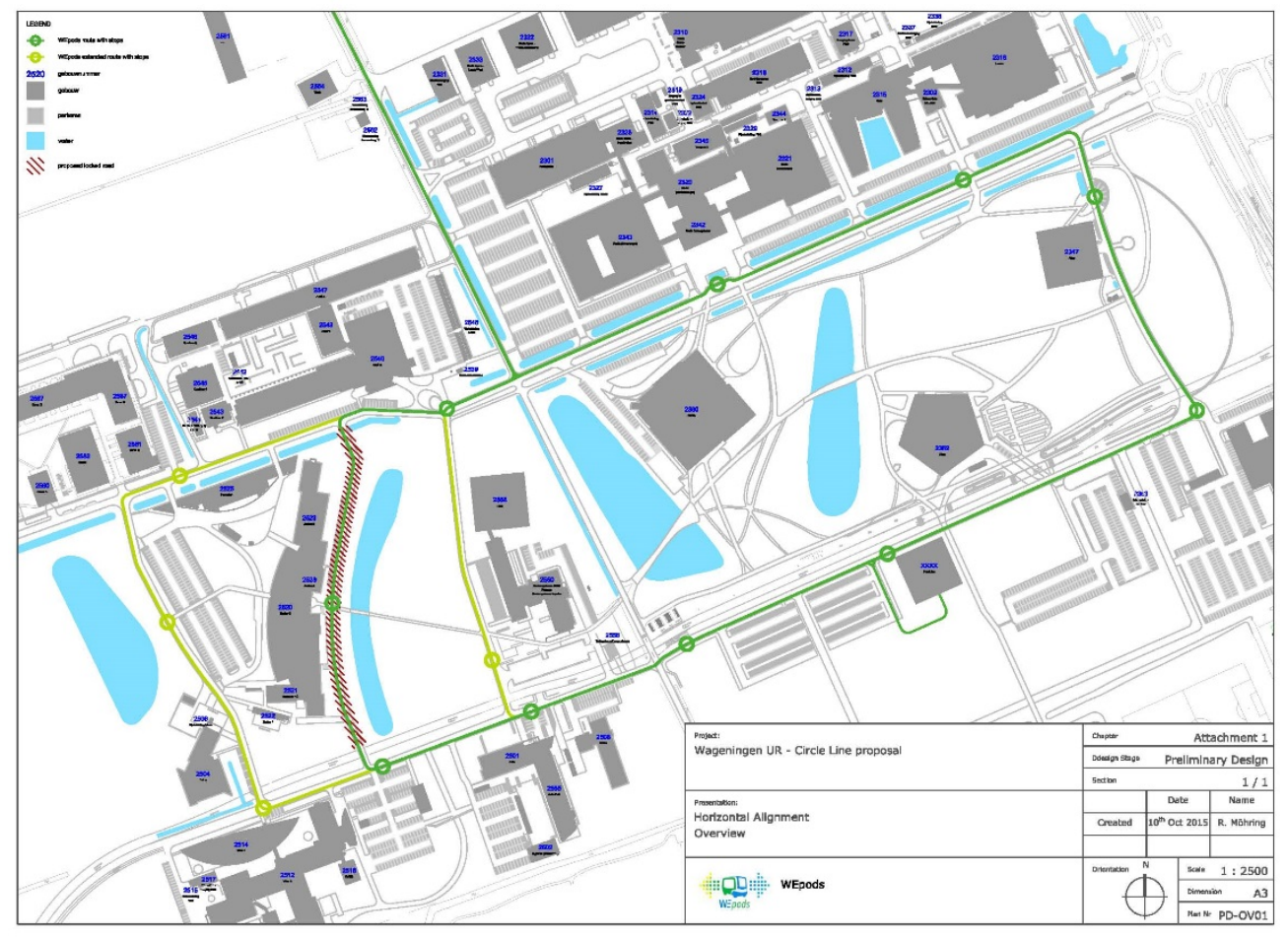


(15.5 mph); during the operational phase, it will be $40 \mathrm{~km} /$ hour ( $25 \mathrm{mph}$ ). The test phase will last from January 2016 until sometime in summer 2016, when regular service will begin. During the test phase, only project test engineers will ride on board the WEPods.

\section{CarPostal}

Another autonomous shuttle manufacturer is the French company NAVYA. In December 2015, it delivered two shuttles, known as ARMA, to its first customer, CarPostal, a Swiss public transportation company. The shuttles will be used in a two-year demonstration in the Swiss city of Sion. The project also includes BestMile, a start-up company formed by engineering graduates from EPFL in Lausanne, who will hande the fleet management of the autonomous vehicles.

Although this project is not the first time autonomous shuttles have been tested in Switzerland, it will be the first time a public transportation company in Europe has used this technology on public roads as part of its service. The shuttles have CarPostal's iconic yellow livery and three-tone horn logo (see Figure 7). Initial testing has already begun in a private cordoned-off area and will continue into spring 2016. If that testing is successful, the second phase will be to operate the shuttles in Sion's old town and tourist center areas starting in summer 2016. Although the maximum capacity of the ARMA is 15 passengers and the maximum speed is $28 \mathrm{mph}$, the project will limit the capacity to 9 passengers and the speed to $12.4 \mathrm{mph}$ (20 km/hour) for safety reasons.

Similar to the CityMobil2 demonstrations, the

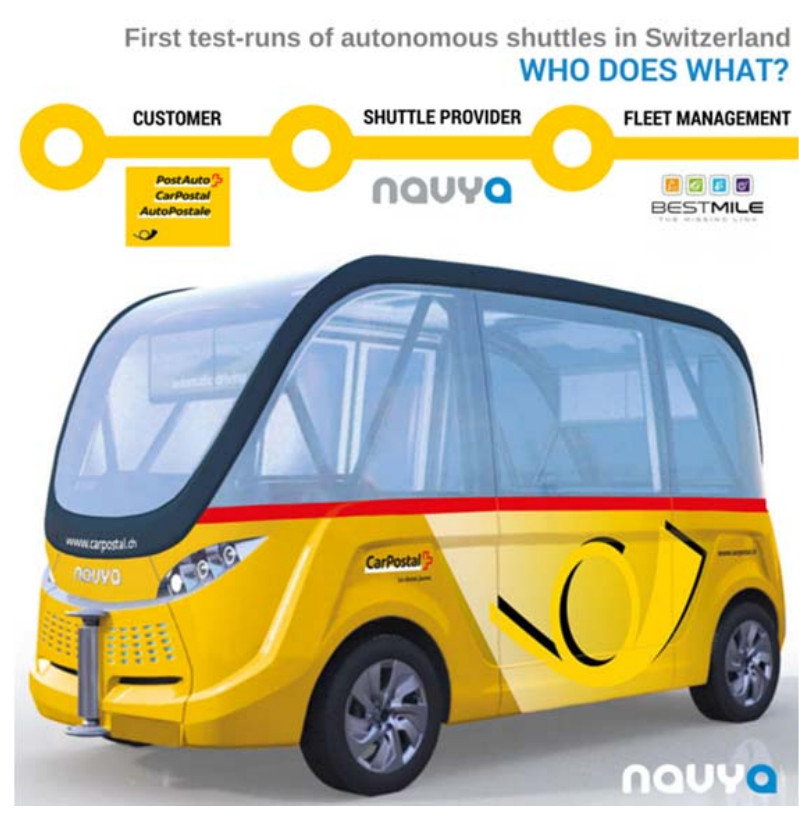

Source: NAVYA

Figure 7. CarPostal ARMA Shuttle shuttles in Sion will have a trained professional on board in case of an emergency. The shuttles do not have a steering wheel, accelerator, or brake pedal, but they do have an emergency button to stop the vehicle. According to CarPostal, its interest in the project is not just to test autonomous vehicle technology but also to determine if these vehicles can provide mobility in regions that currently are not serviced by public transportation. The project still needs legal authorization to operate on public roads. At the time of this report, the project partners were still working on securing that approval.

\section{Contra Costa Transportation Authority}

In October 2015, CCTA in Northern California signed an agreement with EasyMile for a two-year test of two EZ10 autonomous shuttles to determine the potential of autonomous shuttles filling in the gaps of traditional public transportation and addressing the challenge of first-mile, last-mile. CCTA estimates the total two-year budget at $\$ 5$ million, which includes capital investment, testing, operations and 
maintenance, and the costs associated with seeking regulatory approval. CCTA is seeking both private and public investment in the project. As of the time of this report, it had achieved $50 \%$ of its funding goal and was seeking federal and local grants for the remaining $50 \%$.

Their project will have three phases. Phase 1, expected to begin in the summer of 2016, will be controlled testing at GoMentum Station, CCTA's 5,000-acre testing ground for autonomous vehicles on the grounds of the former Concord Naval Weapons Station. This facility has 20 miles of paved roadway and is essentially a miniature city. During this phase, a team comprising engineers from EasyMile and inspectors from CCTA will observe the vehicles as they navigate the test grounds and will perform a series of tests, including:

- $\quad$ Lane tracking

- Traffic signal detection

- Vehicle detection

- Rail crossing detection

- Pedestrian detection and reactions

Based on the results, CCTA may ask EasyMile to make some modifications to the shuttles and perform verification testing before proceeding to the next phase.

During Phase 2, the shuttles will be moved to Bishop Ranch, a 500-acre business park located in San Ramon and home to companies such as AT\&T, Chevron, and General Electric. During Phase 2 testing, the shuttles will run after-hours and on the weekends on one quadrant of the business park that has nonpublic roads.

Once the autonomous navigation of the shuttles has been proven, Phase 3 will begin, during which the shuttles will operate during normal daylight hours with passengers on four blocks of public streets that cut through Bishop Ranch. Similar to the demonstrations that were done in Europe, the CCTA project will include a fleet management component whereby the shuttles are monitored from a remote control room. Before the Phase 3 testing can begin, CCTA has to secure regulatory approval. California law permits testing of autonomous vehicles only on public roads if the vehicle has a steering wheel, brake pedal, and accelerator; the EZ10 shuttles do not have such devices. To overcome this obstacle, Assembly Bill 1592 has been put forth that would permit CCTA to conduct a pilot project on public roads of autonomous vehicles that are not equipped with a steering wheel, brake pedal, and accelerator. The bill, as it is currently written, limits the authorization to CCTA and limits the speed of the autonomous vehicles to less than $35 \mathrm{mph}$. (Note: Florida law is more flexible, requiring only that an autonomous vehicle "have a means to engage and disengage the autonomous technology which is easily accessible to the operator" (319.145 (1)(a), Florida Statutes).

\section{Minnesota Valley Transit Authority}

The original 2015 report included a summary of the GPS-based driver assist system (DAS) used by Minnesota Valley Transit Authority (MVTA) for bus-on-shoulder (BOS) operations. The DAS is a lane- 
keep assist and collision warning system that the operators use when in the shoulder. The Twin Cities Metropolitan area has an extensive network (approximately 250 miles) of BOS operations. Bus operators use the shoulders at their discretion when speeds on the general-purpose lanes drop below $35 \mathrm{mph}$.

The first iteration of the DAS was a prototype developed by the Intelligent Vehicles Laboratory at the University of Minnesota. It was installed on 10 buses that operate on Cedar Avenue, a suburban six-lane highway, and used three forms of feedback: visual, tactile, and haptic. Visual feedback was provided via a head-up display (HUD) and virtual mirror; tactile feedback was provided via a virtual rumbling strip (i.e., a vibrating seat); and haptic feedback was provided via a torque-actuated steering wheel.

In 2015, FTA awarded MVTA \$1.79M to equip 11 more buses with the DAS. This second iteration of the DAS (Gen2 DAS) is an updated and commercialized version developed by MTS Systems Corporation, a private company that hired the original DAS engineers. The Gen2 DAS has several modifications to the original version, chief among which is the elimination of the HUD as a form of visual feedback. It will instead use a series of light emitting diodes (LEDs) and a liquid crystal display (LCD) touch panel. Two amber-colored LEDs will be mounted to the bus's A-pillar (one on the left and one on the right) for lanedeparture warning. One red LED will be mounted on the operator's instrument panel for forward collision warning. The LCD touch panel will be mounted to the left A-pillar and will be used to provide side and forward collision warnings and activate and deactivate the various DAS components.

Another change involves the use of radar. Whereas lidar was used in the original DAS to provide both front and side collision sensing, the Gen2 DAS will use lidar only for the front collision sensing; the side collision sensing will be provided by radar. The Gen2 DAS will retain the haptic feedback of the torqueactuated steering wheel and the tactile vibrating driver's seat.

MTS will begin equipping and testing the MVTA buses in April 2016, and it is expected that the buses will enter into revenue service in June 2016. The Center for Urban Transportation Research (CUTR) at the University of South Florida will conduct a one-year evaluation of the Gen2 DAS. 


\section{Section 2 Autonomous Shuttle Manufacturers}

\section{EasyMile}

EasyMile is a French company based in Toulouse and is a joint venture between Ligier, a vehicle manufacturer, and Robosoft, a high tech company specializing in service robotics. As stated earlier in the report, EasyMile is one of the two vehicle manufacturers for the EU-sponsored CityMobil2 project. In addition to CityMobil2, EasyMile has or will soon have projects in the Netherlands, Singapore, and Northern California. Their latest model is the EZ10, as shown in Figures 8 and 9. For navigation, the vehicle uses a combination of cameras, lidar, and differential GPS.

The EZ10 has the following specifications:

- Capacity: 12 persons (6 sitting and 6 standing)

- Cruising speed: $20 \mathrm{~km} / \mathrm{h}$

- Maximum speed: $40 \mathrm{~km} / \mathrm{k}$

- Propulsion engine: Electric asynchronous

- Autonomy: up to 14 hours of operation

- Battery: Lithium-ion (LiFeP04)

- Battery Charger: 110V - 230V 16A

- Length: 3,928 m / 154.6"

- Width: 1,986 m / 78.2"

- Height: 2,750 m / 108.3“

- Wheelbase: $2,800 \mathrm{~m} / 110.2^{\prime \prime}$

- Payload: $1700 \mathrm{~kg} / 771 \mathrm{lbs}$

- Fully loaded: $2800 \mathrm{~kg} /$ 1,270 lbs

- Vehicle cost: 200,000 to $220,000 €$. (\$223,180 to $\$ 245,498)$

- Annual maintenance costs: $30,000 €(\$ 33,477)$ per year

The EZ10 has three modes of operation: Metro Mode, Bus Mode, and OnDemand Mode. In both the Metro Mode and Bus Mode, the EZ10 operates as a "horizontal lift" (i.e., horizontal elevator) by going back and forth in a single traffic

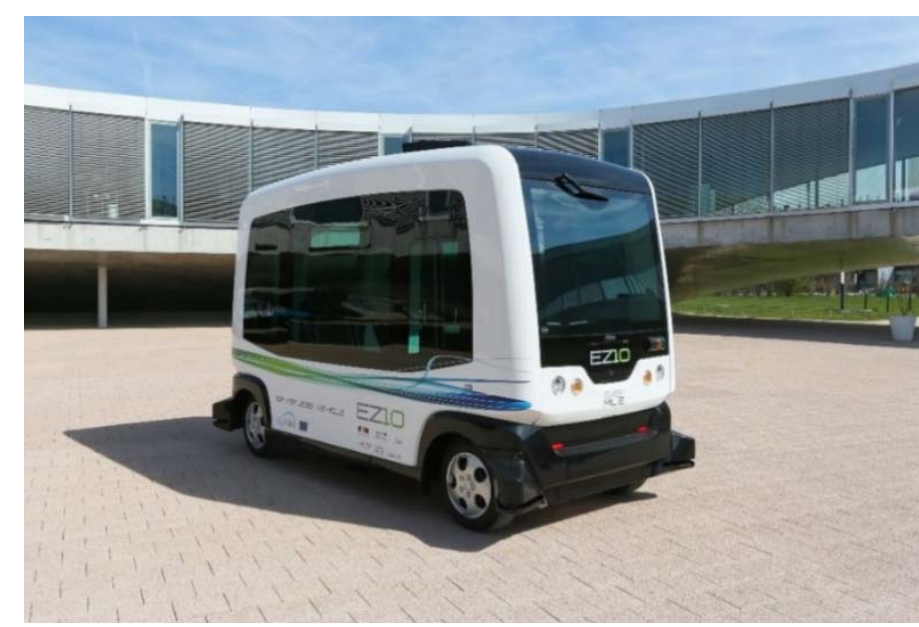

Source: EasyMile

Figure 8. EZ10 Autonomous Electric Shuttle by EasyMile

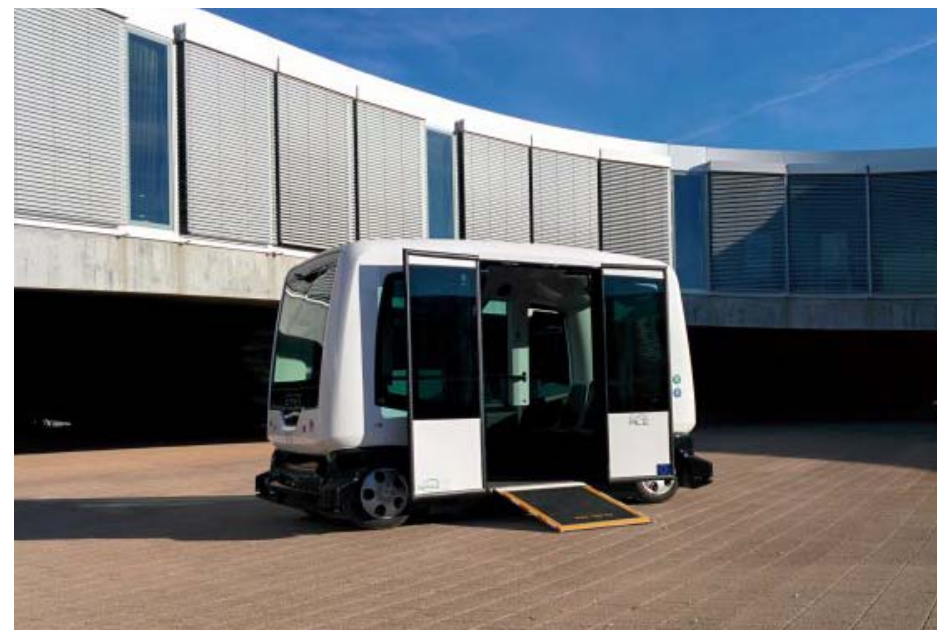

Source: EasyMile

Figure 9. EZ10 Model Showing Handicap Accessibility by EasyMile 
lane or on a loop. In Metro Mode, the vehicle follows a set schedule and stops at all stations. In Bus Mode, the vehicle will stop only at stations if there is a passenger request, either by a passenger on the vehicle or by a passenger at a station who presses a call button. In On-Demand Mode, the vehicle responds to service requests sent by a smartphone app.

\section{NAVYA}

NAVYA is a French company based in Paris and Lyon that specializes in electric autonomous vehicles. It launched its autonomous shuttle, the ARMA, in October 2015 (see Figure 10), which uses a combination of four sensors: LIDAR, GPS, odometer, and stereovision camera. The LIDAR is used for obstacle detection and creating 3-D cartography, the GPS for vehicle location, the odometer for speed determination, and the camera for obstacle detection and analysis of the

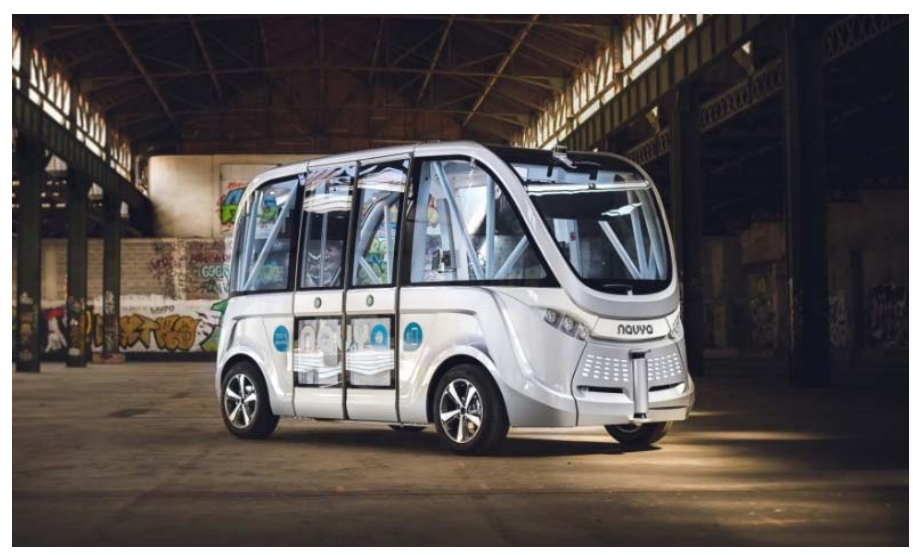

Source: NAVYA

Figure 10. ARMA Autonomous Electric Shuttle environment.

The NAVYA ARMA has the following specifications:

- Capacity: 15 passengers (8 sitting and 7 standing)

- Cruising speed: $16 \mathrm{mph}$

- Maximum speed: $28 \mathrm{mph}$

- Propulsion engine: Battery

- Autonomy: 5-12 hours, depending on charging system and battery capacity

- Length: 4.75 meters $/ 15.58 \mathrm{ft}$

- Width: 2.05 meters $/ 6.73 \mathrm{ft}$

- Height: 2.55 meters $/ 8.37 \mathrm{ft}$

- Payload: 4630 - 5180 lbs empty (depending on optional equipment)

- Fully loaded: 6,945-7,500 lbs

- Vehicle cost: $200,000 €$ each $(\$ 223,180)$

- Charging station cost: $20,000 €$ each $(\$ 22,558)$

- Annual operating cost: $90,000 €(\$ 101,511)$

In addition to the project in Sion, NAVYA has upcoming projects in the French cities of Lyon and Paris. The project in Lyon is scheduled to begin in June 2016 and will operate a shuttle line in the smart city neighborhood of Confluence. The project in Paris will operate shuttles on open road between two main rail stations over the Seine River. 